\title{
Impact of ICT Driven QA Framework on the Institutions of Higher Learning: India
}

\author{
Pratibha Singh
}

\begin{abstract}
Quality Assurance is presently entrusted with the national level accreditation agencies in India. National Assessment and Accreditation Council (NAAC) has made pioneering impact in past 25 years and has gained an acceptable level of credibility in higher education sector of the country. This study is about the efforts made by NAAC in bringing paradigm shift by launching a data driven framework for assessment and accreditation of institutions. It is attempted to analyze the impact of introducing ICT enabled bench-marking based NAAC's framework on the performance of institutions. There are around 1546 institutions in various cycles completing this new assessment process as on $31^{\text {st }}$ December 2020; performance of class-wise institutional categories is analyzed examine the possible patterns as well as to focus on reasons for such patterns.
\end{abstract}

Index Terms-Revised accreditation framework (RAF), CGPA, criterion, grade, peer team.

\section{INTRODUCTION}

Higher education system of India is third largest in the world with the enrolment of around 38 million students [1]. Tertiary education is imparted in various universities and colleges that are offering degree, diploma and certificate programmes including professional programmes. The responsibility of regulation and maintenance of standards in higher education institutions is mainly coordinated by University Grants Commission (UGC) [2] as well other regulatory bodies depending upon specialized field of education. Due to great demand of increasing access as well as to improve the gross enrolment ratio of higher education in country, Government has taken several initiatives more importantly allowed privatization of education in early 90's. Although this expansion has impacted the GER to rise as targeted but at the same time has raised the issues with quality of education. This development of higher education in India in the recent years has been impacted by many socio-political influences. Structured modeling of Higher education system has been much long awaited requirement and recently, with launching of new national education policy-NEP 2020 by Union Government, it is expected to be met.

\section{A. NAAC: National Agency for Quality Assurance}

NAAC is an autonomous organization of UGC established in 1994 with the pursuance of national policy on education (NPE) 1986 [3] and programme of action (POA) 1992 thereon. Role of NAAC is to assess Quality of education in Higher Education Institution (HEI's) and provide an

Manuscript received June 11, 2021; revised September 3, 2021.

Pratibha Singh is with National Assessment and Accreditation Council, Delhi, India (e-mail: prat_ibh_a@yahoo.com). objective data to various stakeholders such as students, parents, employers, funding agencies and Government by grading them. These performance grades are often linked to various schemes of the government for providing resources to the institutions and other stakeholders. NAAC is working at the level of institutional accreditation. There are few more mechanisms existing in country which work towards quality assessment of institutions by ranking them [4] or by performing audits. National Board of Accreditation (NBA) [5] is another agency in India, for assessing and accrediting professional and engineering programmes. NBA maintains credibility of technical education programmes by being an authorized signatory of Washington Accord. Apart from this there are some private agencies working towards quality assurance for business schools and hospitals. Despite making several efforts by these agencies, institutions are not moving to become a part of the quality journey when the status of accreditation at country level is seen. The accreditation covered at national level and in most of the states is limited to a range between $20-30 \%$ both at institutional level as well as at programme level. The reason for this status of quality is reflected in many reports published in context of higher education [6]-[8]. Some more prominent once are: commercialization of education being inherent character with privatization, lack of motivation of institutions and the staff towards quality upliftment, lack of funding and resources, existence of large number of vacancies in staff to be appointed, poor infrastructure etc. Therefore, a layered structure of higher education institutions is seen in the country. With so many different layers in quality standards, diversity widens specifically at field of study, at level of offerings, at availability of resources and at socio-economical background. With the large diversity of educational institutions in India, it is challenging to capture diversity by various data driven tools used for quality assessment.

NAAC's methodology of assessing the institutions in RAF is based on seven criterion tool and CGPA scores arrived at for individual institution is a result of weighted sum of the score obtained in each component of the framework. Criterion used in framework covers all areas of educational planning for an institution and these are defined as follows:

1) Curricular Aspects

2) Teaching-Learning and Evaluation

3) Research, Innovations and Extension

4) Infrastructure and Learning Resources

5) Student Support and Progression

6) Governance, Leadership and Management

7) Institutional Values and Best Practices

Each criteria $(\mathrm{Cr})$ is made up of few key indicators (KIs) and each key indicator is further delineated to various performance matrices. The internal weight distribution of 
individual criteria, key indicator and individual metric within the key indicator is arrives at by huge consultation of field experts and academicians. The CGPA and the grade for the institution will be calculated using the formula given as follows:

$$
\text { Institutional CGPA }=\frac{\sum_{i=1}^{7} C r W G P_{i}}{\sum_{i=1}^{7} W_{i}},
$$

where CrWGP is total weighted grade points for individual criteria and $\mathrm{Wi}$ is the total weight across criteria.

Let for criterion $j$, where $\mathrm{j}=1,2, \ldots, 7, \mathrm{KI}$ represent the Key indicator then

$$
\operatorname{CrGPA}_{j}=\frac{\sum_{i=1}^{m} K I W G P_{i}}{\sum_{i=1}^{m} W_{k}}
$$

where $m$ refers the number of key indicators in criteria, KIWGP is total weighted grade points for key indicator and $\mathrm{W}_{\mathrm{K}}$ is the total weight of the key indicator.

Key indicator weighted grade point is the function of the individual quantitative metric $\left(\mathrm{Q}_{\mathrm{NM}}\right)$ score, which in turn dependent on the data of the institution and evaluation benchmark set for the metric. The proportion of $\mathrm{Q}_{\mathrm{NM}}$ and $\mathrm{Q}_{\mathrm{LM}}$ metrics in RAF comes to around 70:30 percentage for institutions.

The framework used for assessment is revised frequently from time to time to suit the requirements of the stakeholders of higher education. This study focuses on measuring the impact of recent revision which is considered as paradigm shift in the history of NAAC as well as the core philosophy of Assessment and Accreditation process.

\section{B. Institutions and Data Analysis}

For the purpose of analysis, firstly the institutions are classified on the basis of their similar specialized character i.e., Women Institutions, Engineering Institutions, Autonomous Institutions, and Government Institutions. The performance is compared for each such group of institutions accredited in earlier method with their respective performance post revision. The objective was to identify a pattern in performance and possibly to find out the reasons for observed patterns if any marked up by these classes of institutions. Performance analysis and comparison for these different classes of institutions is presented in subsequent sections.

\section{1) Institution for women}

An institution which enrols only female students in all its programmes is categorised as Institution for Women. Such institutes may or may not have male teaching and non-teaching staff. Women institutions play a pivotal role in women empowerment, apart from this they are also important for improving access provide supportive campus climates, leadership development, and function as symbols within national systems of higher education.

The gender inequality is more prominent for the developing countries compared to developed countries [9]. While women have legal access to coeducation institutions everywhere in the world, but due to their own values, reservation exist for number of regions where religious and political extremists prohibit coeducation or, in some cases, any education for women and girls.

As far as India is concerned women enrolment has risen from less than $10 \%$ of the total enrolment at the time of Independence to $49 \%$ in 2019-20. The total enrolment [1] in higher education has grown considerably to 38.5 million with 19.6 million boys and 18.9 million females. Female per 100 male students has also risen significantly in central universities, deemed universities, and government-aided institutions. But there is another side. The share of male students enrolled in engineering and technology is $71.1 \%$ compared to female enrolment, which is just $28.9 \%$.

According to AISHE data [1] there are 17 Universities exclusively for women and 4551 women colleges in India. Uttar Pradesh is having highest number of women colleges among the states with number 785 while Rajasthan is at the second rank in the list with 678 colleges. State-wise maximum and minimum number of women colleges are given in Table I.

TABLE I: STATE-Wise NUMBER OF WOMEN COLLEGES

\begin{tabular}{l|c|l|c}
\hline \multicolumn{3}{|c|}{ Maximum Number } & \multicolumn{2}{c}{ Minimum Number } \\
\hline $\begin{array}{l}\text { Name of the } \\
\text { state }\end{array}$ & $\begin{array}{l}\text { Number of } \\
\text { colleges }\end{array}$ & Name of the state & $\begin{array}{l}\text { Number } \\
\text { colleges }\end{array}$ \\
\hline Uttar Pradesh & 785 & Arunachal Pradesh & 1 \\
\hline Rajasthan & 678 & $\begin{array}{l}\text { Dadra and Nagar } \\
\text { Haveli }\end{array}$ & 1 \\
\hline Tamil Nadu & 412 & Daman and Diu & 1 \\
\hline Maharashtra & 349 & Goa & 2 \\
\hline Karnataka & 279 & Nagaland & 2 \\
\hline \multicolumn{4}{c}{ Source: AISHE Portal 2019-20 report. }
\end{tabular}

\section{2) Autonomous colleges}

For affiliated colleges status of autonomy is granted by UGC. UGC has introduced a scheme of Autonomous College keeping in view the objectives of the National Education Policy (1986-92) [3]. All type of colleges viz. Government, aided, unaided or self financing category under Section 2(f) of the UGC Act are eligible under this Scheme. Criteria [10] for identification of institutions for grant of autonomy are as follows:

Criterion: NAAC score greater than equal to 3.26 and less than 3.5 , or at least 3 programmes accredited by NBA with not less than 675 score

Sub clause: status is granted after visit.

Criterion: NAAC score greater than equal to 3.51, or minimum three programmes with minimum score of 750 .

Sub clause: status is granted without visit

1) Academic reputation and previous performance in university examinations and its academic/co-curricular/extension activities in the past.

2) Academic/extension achievements of the faculty.

3) Quality and merit in the selection of students and teachers, subject to statutory requirements in this regard.

4) Adequacy of infrastructure, for example, library, equipment, accommodation for academic activities, etc.

5) Quality of institutional management.

6) Financial resources provided by the management/state government for the development of the institution.

7) Responsiveness of administrative structure.

8) Motivation and involvement of faculty in the promotion of innovative reforms. The Parent University awards degrees to the students, evaluated and recommended by colleges. Autonomous colleges that have completed three-year terms can confer the degree under their title 
with the seal of the university.

As per list available dated $16^{\text {th }}$ June 2021 , on UGC (UGC, 1956) website there are 832 autonomous colleges in India which are geographically distributed across various states. The top five states having maximum and minimum number of autonomous colleges are shown in Table II.

TABLE II: STATE-WiSE NuMBER OF AUTONOMOUS COLLEGES

\begin{tabular}{l|l|l|cc}
\hline \multicolumn{3}{c|}{ Maximum Number } & \multicolumn{3}{c}{ Minimum Number } \\
\hline $\begin{array}{l}\text { Name of the } \\
\text { state }\end{array}$ & $\begin{array}{l}\text { Number } \\
\text { colleges }\end{array}$ & $\begin{array}{l}\text { Name of the } \\
\text { state }\end{array}$ & $\begin{array}{l}\text { Number } \\
\text { colleges }\end{array}$ & of \\
\hline Tamil Nadu & 227 & Haryana & 1 \\
\hline Maharashtra & 119 & Goa & 2 \\
\hline Andhra Pradesh & 116 & Manipur & 2 \\
\hline Karnataka & 81 & Assam & 2 \\
\hline Telangana & 74 & Bihar & \\
\hline \multicolumn{4}{c}{ Source: UGC retrieved on August 2021. }
\end{tabular}

\section{3) Technical institutions}

To develop the skilled manpower and in turn enhancing industrial productivity and improving quality standard of life, technical education plays a key role. Technical Education extends towards management, architecture, town planning, pharmacy, applied arts \& crafts, hotel management and catering technology apart from the courses on engineering \& technology. Technical education centres and colleges were established in India out of necessity from the period of British rulers for construction and maintenance of public buildings, roads, canals and ports and for the training of artisans and craftsmen for the use of instruments and apparatus needed for the army, the navy and the survey department. As per AISHE report 2019-20 there are 177 Technical universities and 2678 colleges in India offering Engineering and Technology programmes (which excludes IIT's and NITS).

Both NAAC as well as NBA considers technical Institutions for accreditation, but NBA generally takes programme-wise accreditation where as NAAC considers Institutional Accreditation. The state-wise class for maximum and minimum number of Institutions is given in Table III.

TABLE III: STATE-WISE NUMBER OF TECHNICAL INSTITUTIONS

\begin{tabular}{l|c|l|lc}
\hline \multicolumn{3}{c|}{ Maximum Number } & \multicolumn{2}{c}{ Minimum Number } \\
\hline $\begin{array}{l}\text { Name of the } \\
\text { state }\end{array}$ & $\begin{array}{l}\text { Number of } \\
\text { colleges }\end{array}$ & $\begin{array}{l}\text { Name of the } \\
\text { state }\end{array}$ & $\begin{array}{l}\text { Number } \\
\text { colleges }\end{array}$ & 1 \\
\hline Tamil Nadu & 455 & Mizoram & 1 \\
\hline Maharashtra & 345 & Nagaland & 1 \\
\hline Andhra Pradesh & 273 & $\begin{array}{l}\text { Dadra and } \\
\text { Nagar Haweli }\end{array}$ & 2 \\
\hline Gujarat & 207 & Chandigarh & 2 \\
\hline Telangana & 191 & $\begin{array}{l}\text { Sikkim, } \\
\text { Meghalaya }\end{array}$ & \\
\hline
\end{tabular}

\section{4) Government colleges}

Government colleges considered in various reports fall in two classes, Institutions run by Government, or the Institutions run by Private Management or society but receiving grants from Government. Characteristics of these colleges are described as follows:

1) Government Degree Colleges: Established and managed by State Government. Cost of infrastructure and staff salary is borne by State Government.

2) Government-aided Colleges: Established by private management as per affiliation norms of public university and governed by State Government. Only staff salary is borne by the State Government. In some of these colleges there are self-financed courses as well.

Government degree colleges in India are public-sector educational institutions managed mainly by government and governed by guidelines and regulations issued by regulatory bodies like UGC, AICTE, NCTE and few others. The aim behind the formation of the government degree colleges is to provide higher education to undergraduates, postgraduates and doctoral research scholars in various streams and courses recognized by UGC (UGC, 1956). Many provisions are made by government for the purpose of grants. The recognition of the institutions under 2 (f) and 12 (B) act of UGC for receiving central grant, RUSA, TEQUIP and many more state government schemes facilitate funds to the institutions. The government degree college as the institute of higher education are administered and controlled by the principal who serves as the head. Teachers (Assistant Professor, Associate Professor, and Professor) are appointed through Public Service Commission (a government body under the articles 315 to 323 of the Constitution of India) of central and state governments. As per AISHE data 2019-20, India has 8565 Government Colleges; states with minimum and maximum number of government colleges is given in Table IV.

TABLE IV: STATE-WISE NUMBER OF GOVERNMENT COLLEGES

\begin{tabular}{l|c|l|c}
\hline \multicolumn{2}{c|}{ Maximum Number } & \multicolumn{2}{c}{ Minimum Number } \\
\hline Name of the state & $\begin{array}{c}\text { Number of } \\
\text { colleges }\end{array}$ & Name of the state & $\begin{array}{c}\text { Number of } \\
\text { colleges }\end{array}$ \\
\hline Uttar Pradesh & 827 & Lakshadweep & 0 \\
\hline Karnataka & 707 & $\begin{array}{l}\text { Dadra and Nagar } \\
\text { Haveli }\end{array}$ & 3 \\
\hline Rajasthan & 668 & Daman and Diu & 6 \\
\hline Madhya Pradesh & 620 & $\begin{array}{l}\text { Andaman and } \\
\text { Nikobar }\end{array}$ & 8 \\
\hline Maharashtra & 535 & Sikkim & 14 \\
\hline
\end{tabular}

Source: AISHE Portal report 2019-20.

\section{Framework for Assessment and Accreditation by NAAC}

\section{1) The earlier process}

The assessment process before introducing Revised Accreditation Framework (RAF), i.e., before 2017, now-on will be referred as accreditation in earlier process. Earlier process was completely based on peer judgment and had been viewed as lacking objectivity. Process was starting with submission of application and submission of Self Study Report (SSR). After analyzing fact and figures given in SSR by institution, visiting team used to make reports (PTR) of assessment as well as was assigning criteria-wise scores in parity to the report. The assessment report forms the guiding document for future quality enhancement and subsequent assessment. The A \& A process flow in earlier methodology is depicted in the in Fig. 1.

The self-study report submitted by institution in earlier process used to be written on the basis of indicators of quality in education but largely remained unstructured as far as analysis is concerned. The method was time and again viewed as subjective due to large inter team variance in the assessing the similar category of Institution. 


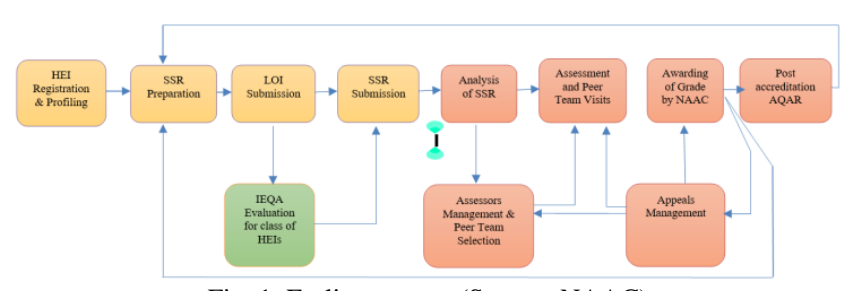

Fig. 1. Earlier process (Source: NAAC)

\section{2) Overall workflow in RAF}

RAF process that presently NAAC is following is an outcome of regular revision process held in July 2017, which is largely seen as introducing data driven assessment framework. The proportion of data-based matrices which forms almost $70 \%$ of the entire weightage is validated by third party. This has made the paradigm shift in the philosophy of Assessment and Accreditation for Higher education Institutions which is based on peer evaluation in most of the countries.

The method brought out on one hand objectivity in Assessment \& Accreditation process on other hand it is more focused towards outcomes. However, the impact of such automation in the performance of the institution is worth to be analyzed and this study is the effort made to do so. Process flow of RAF is depicted in Fig. 2.

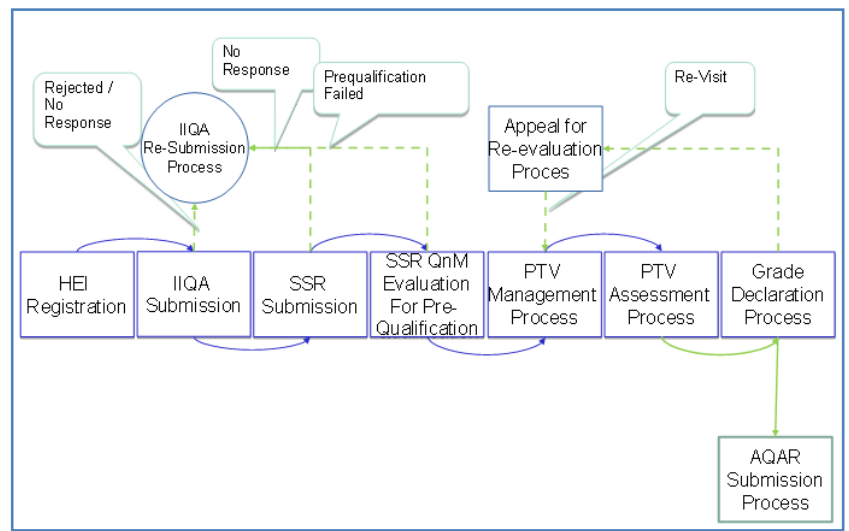

Fig. 2. Revised methodology for assessment and accreditation (Source: NAAC).

\section{Materials AND MethodS}

NAAC maintains the performance outcome of institutions accredited on website [11] (NAAC, 1994) accessible through public dashboard. Accreditation list is a function of time as far as number of institutions is concerned, as it is granted for a period of 5 years usually or for 7 years in few special cases. The cut-off date considered for analysis in this study is $1^{\text {st }}$ February 2021 for fetching data from dashboard. The total number of Institutions accredited by NAAC having valid accreditation till December 2020 includes 5387 colleges and 318 Universities. CGPA score and grade are fetched for cycle 2 , cycle 3 and cycle 4 institutions in RAF and their respective cycle in earlier process. Accordingly, performance of four institutional classes is considered viz. Government Colleges, Engineering College, Autonomous Colleges and Women Colleges and compared for the purpose of analyzing impact of data driven assessment method.

\section{ANALYSIS OF RESULTS}

The institutions assessed in earlier framework made the pattern showing performances dominating in either A grade or B grade irrespective of class of the institution as depicted in Fig. 3. A performance plot of institutions accredited in RAF is shown in Fig. 4. From the plot, it is quite clear that institutional performances in RAF are more drifting towards grade B and grade A institutions are lesser. Class-wise performance for specific group of institutions focused to show comparison between the earlier and revised framework is depicted in Figs. 5-8.

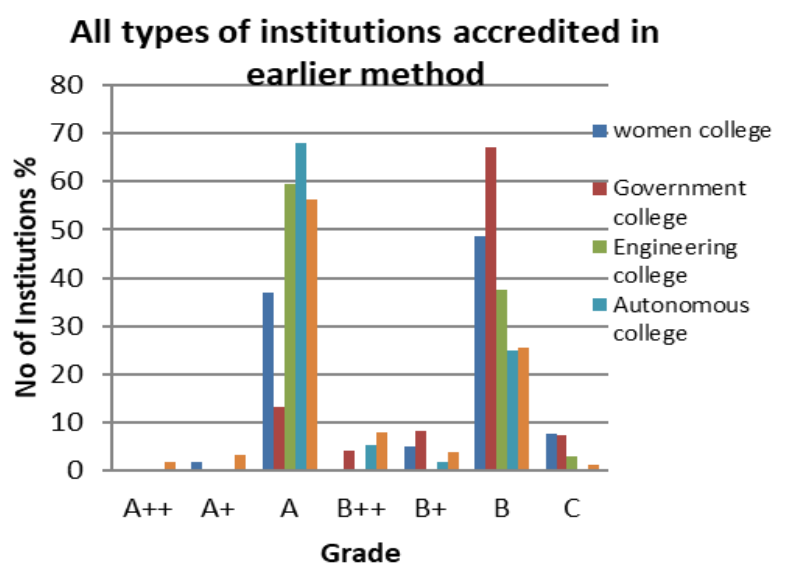

Fig. 3. Performance of institution on 7 point grade accredited in earlier methodology.

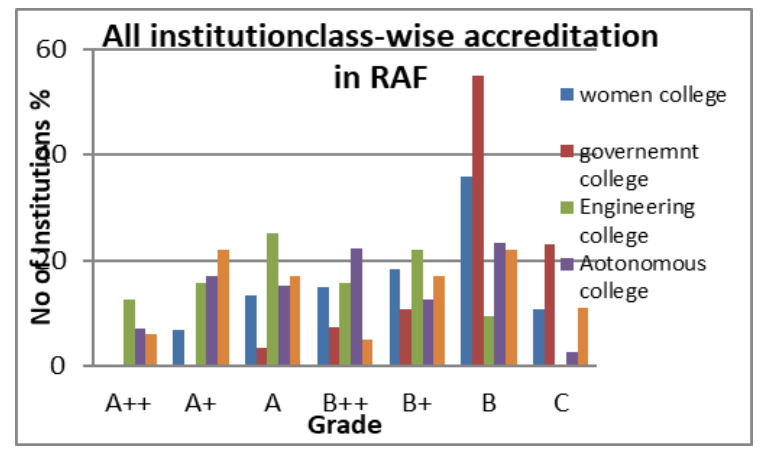

Fig. 4. Performance of institution on 7 point grade accredited in RAF.

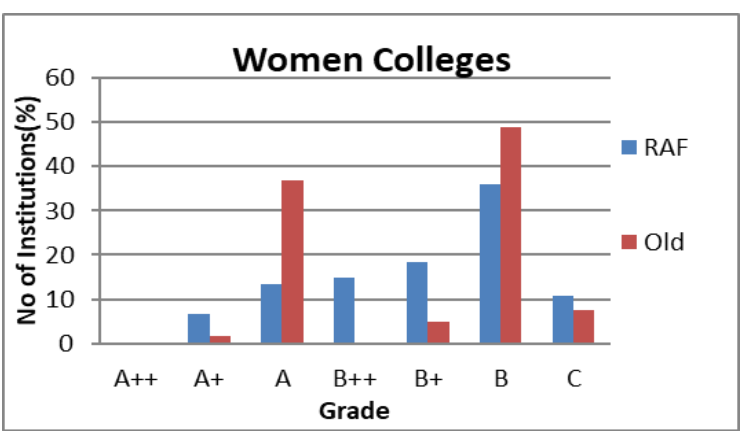

Fig. 5. Performance of institution on 7 point grade for women colleges.

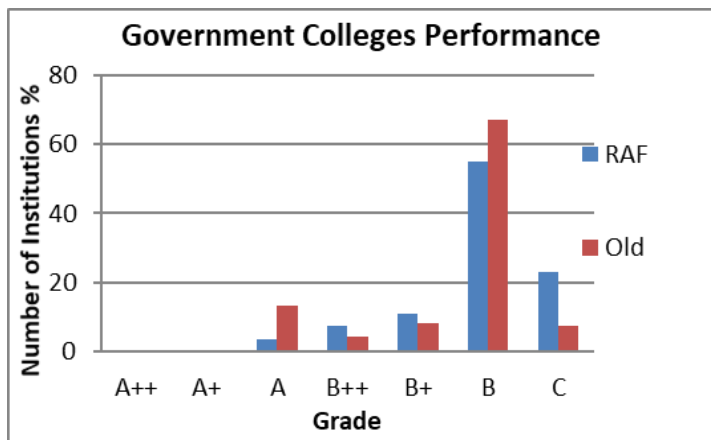

Fig. 6. Performance of institution on 7 point grade for government colleges. 


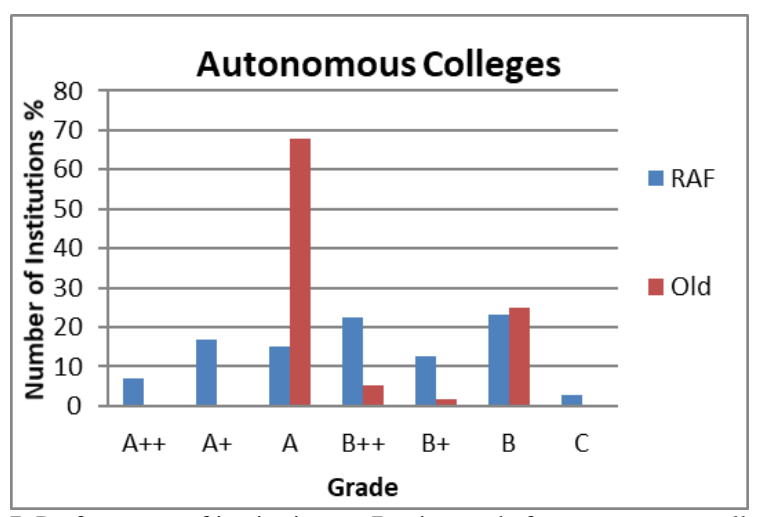

Fig. 7. Performance of institution on 7 point grade for autonomous colleges.

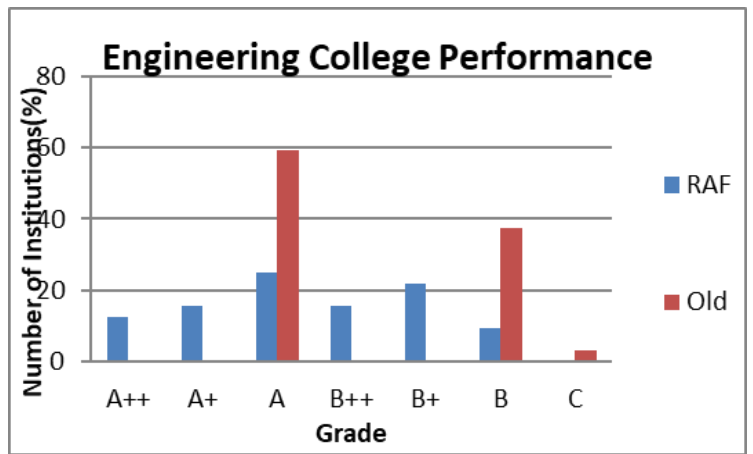

Fig. 8. Performance of institution on 7 point grade for engineering colleges.

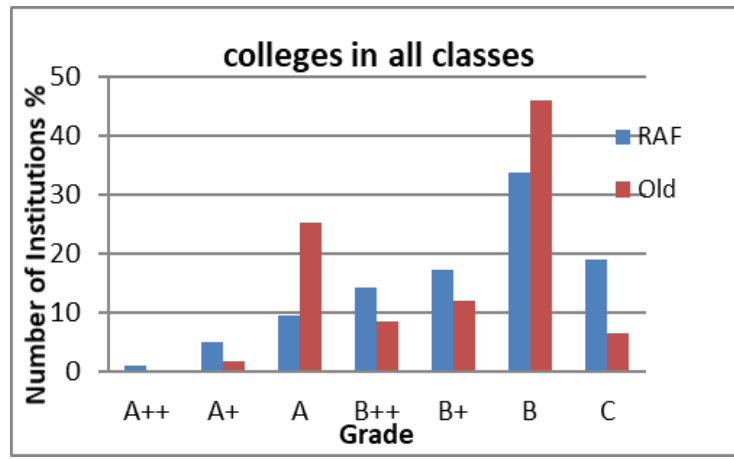

Fig. 9. Performance of institution on 7 point grade for colleges all inclusive.

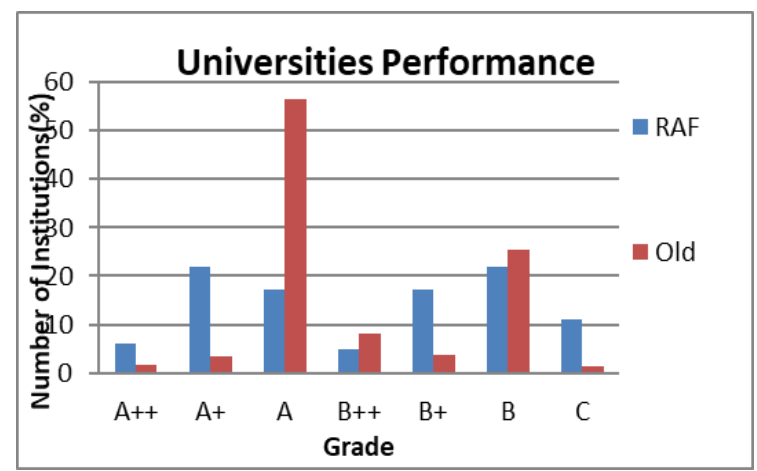

Fig. 10. Performance of institution on 7 point grade for universities.

Overall performance of college all inclusive and universities is plotted and shown in Fig 9-10. The plots affirm the pattern of two grade classification for both universities and colleges in earlier method. The total number of institutions for which these plots are made is given in Table 5. However, the previous performance for the class of institutions also exist in non-CGPA system therefore few class-wise cases are dropped for comparison. Table 6 gives the statistics of drop or rise in the performance in RAF in comparison to earlier process in groups $\mathrm{A}, \mathrm{B}, \mathrm{C}$. The indication ' $\mathrm{D}$ ' mentioned in table is for declining performance and ' $\mathrm{R}$ ' is for rising performance of RAF accredited institution compared to earlier methodology. A group of central range of grades (i.e., $\mathrm{A}, \mathrm{B}++$ and $\mathrm{B}+$ ) is formed and in terms of $\%$ share out of all grades, performance comparison is given in Table VII between RAF and earlier process.

After comparison of grade, CGPA comparison is also done for RAF accredited institutions with previous CGPA score. The plots for such accredited institutions are shown in Figure 11-14. Table 8 gives the class of institutional CGPA performance comparison for RAF accredited institution with reference to their own previous CGPA performance. From which it is found out that there is net degradation in the performance of all classes of institutions with an exception for technical institutions.

TABLE V: NUMBER OF INSTITUTIONS ACCREDITED IN BOTH EARLIER AND NEW FRAMEWORK

\begin{tabular}{|c|c|c|c|c|c|}
\hline Sl. No. & Women & Government & Autonomous & Engineering & Universities \\
\hline Total Number of Institutions in RAF & 170 & 258 & 128 & 301 & 79 \\
\hline Number of Institutions in RAF accredited in cycle 2, 3, 4 & 120 & 122 & 112 & 32 & 29 \\
\hline
\end{tabular}

TABLE VI: PERFoRMANCE COMPARISON OF REVISED METHODOLOGY OVER THE EARLIER METHODOLOGY

\begin{tabular}{c|ccc}
\multicolumn{5}{c}{ OVER THE EARLIER METHODOLOGY } \\
\hline $\begin{array}{c}\text { Type of the } \\
\text { college/Grade }\end{array}$ & $A$ & $B$ & $C$ \\
\hline Women-RAF & $20(\mathrm{D})$ & $69.16667(\mathrm{R})$ & $10.8333(\mathrm{R})$ \\
\hline Women-Earlier & 38.655 & 53.7815 & 7.563 \\
\hline Government-RAF & $3.2786(\mathrm{D})$ & $72.95(\mathrm{D})$ & $22.95(\mathrm{R})$ \\
\hline Government-Earlier & 13.11 & 79.508 & 7.37 \\
\hline Engineering-RAF & $53.125(\mathrm{D})$ & $46.875(\mathrm{R})$ & $0(\mathrm{D})$ \\
\hline Engineering-Earlier & 59.375 & 37.5 & 3.125 \\
\hline Autonomous-RAF & $39.285(\mathrm{D})$ & $58.035(\mathrm{R})$ & $2.678(\mathrm{R})$ \\
\hline Autonomous-Earlier & 67.857 & 32.14 & 0 \\
\hline Universities-RAF & $45.12(\mathrm{D})$ & $43.90(\mathrm{R})$ & $10.97(\mathrm{R})$ \\
\hline Universities-Earlier & 61.44 & 37.28 & 1.27 \\
\hline
\end{tabular}

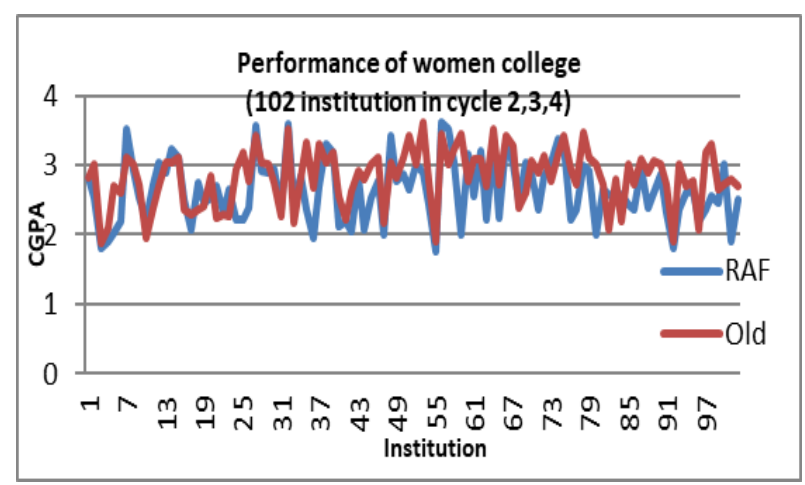

Fig. 11. Women college in RAF. 
TABLE VII: PERFORMANCE COMPARISON OF REVISED METHODOLOGY OVER THE EARLIER METHODOLOGY IN CENTRAL GRADES

\begin{tabular}{l|ll}
\hline $\begin{array}{l}\text { Class of } \\
\text { Institutions }\end{array}$ & $\begin{array}{l}\text { RAF (\% of institution in } \\
A, B++ \text { and } B+)\end{array}$ & $\begin{array}{l}\text { Earlier (\% of institution } \\
\text { in } A, B++ \text { and } B+)\end{array}$ \\
\hline Women & 42.66 & 42.01 \\
\hline Engineering & 62.5 & 59.375 \\
\hline Autonomous & 50 & 75 \\
\hline Government & 21.31 & 25.40 \\
\hline Universities & 39.02 & 68.22 \\
\hline
\end{tabular}

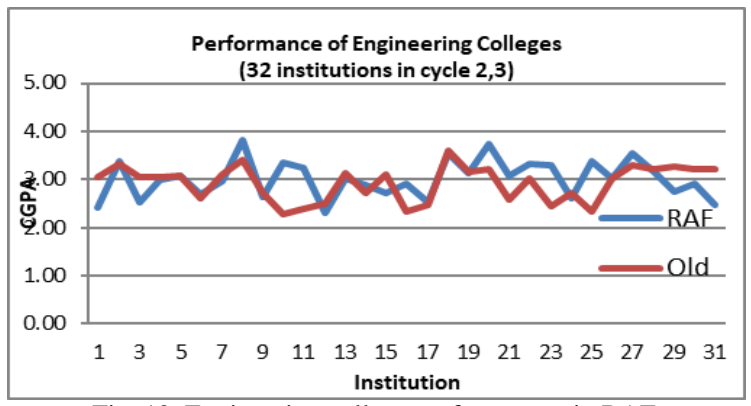

Fig. 12. Engineering college performances in RAF.

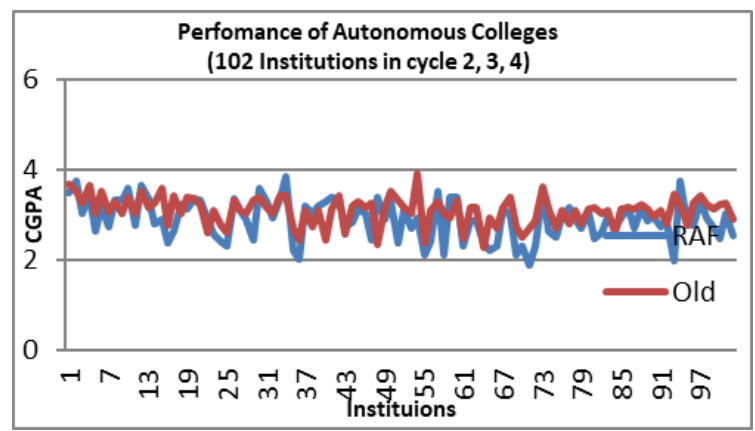

Fig. 13. Autonomous college performance vin RAF.

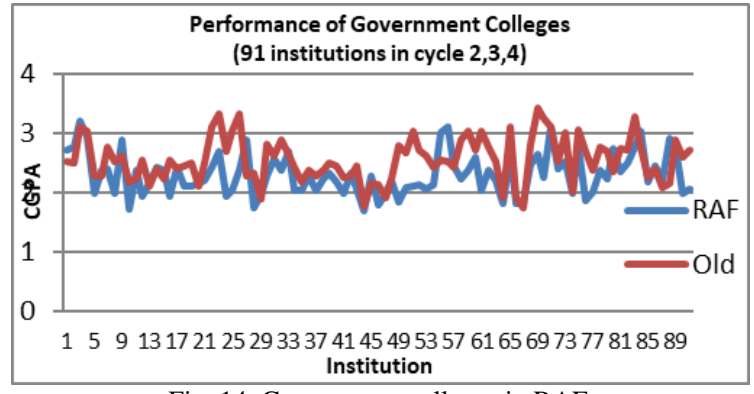

Fig. 14. Government colleges in RAF.

TABLE VIII: OVERALl PERFoRMANCE CATEGORY — WiSE TO SEE NET RESULT

\begin{tabular}{c|cccc}
\hline Type of the College & Negative & Positive & Zero & Net \% \\
\hline $\begin{array}{c}\text { Government } \\
\text { (in 2/3/4 cycle) }\end{array}$ & 64 & 26 & 1 & -8.72 \\
\hline $\begin{array}{c}\text { Engineering } \\
\text { (in 2/3cycle) }\end{array}$ & 15 & 14 & 2 & 4.48 \\
\hline $\begin{array}{c}\text { Women } \\
\text { (in 2/3/4 cycle) }\end{array}$ & 65 & 33 & 2 & -5.66 \\
\hline $\begin{array}{c}\text { Autonomous } \\
\text { (in 2/3/4 cycle) }\end{array}$ & 71 & 29 & 2 & -5.87 \\
\hline
\end{tabular}

Results show that Engineering and Technology group of colleges are showing positive performance in comparison to group of general educational institution. The performance of Government colleges remained at lowest level and is of great concern. The performance of the institution in earlier method which largely created 2 category Institutions either 'A' or ' $B$ ' is highly indicative of human perception. There is no such pattern reflected in the revised methodology; however, the overall declining performance distribution so obtained in
RAF prompted to find out the reasons. Out of this study some of the probable causes identified are given as follows:

1) Smaller number of institutions in RAF in comparison with the number of institutions accredited in earlier method.

2) Lack of familiarity and preparedness for this new ICT based Assessment framework.

3) Introduction of some new metrics in the tool for measuring performance.

4) Lack of availability of third-party sources for validation and verification of academic data. Even if data is maintained by other agencies but time reference used for collecting data is different and with specific focus as per the requirement. Further machine readable structured data is only available in AISHE portal, while other sources maintain data in their own way which make it difficult to be used for automation.

5) Although specialized indicators were integrated in the methodology to cater assessment of specialized group of institutions, but often stakeholders report the issues of insufficiency to capture quality for specific class of intuitions.

6) Data driven tool used for assessment and accreditation has resulted in many merits such as increasing objectivity, reducing scope for corruption, enhancing scope for comparability among institutions, observability of trending patterns in quality etc.

7) Benchmarking based data driven method although has received a lot of appreciation by stakeholders on account of advantages mentioned above, but suffers from drawback of driving quality more towards compliance culture.

8) Component of human bias in assessing institutions in earlier framework which is used as reference point for comparison.

\section{CONCLUSION AND FutURE SCOPE}

After introducing RAF, some studies regarding region-wise, state-wise performance and Overall performance in RAF based on some select data have been attempted recently [12]-[15], however to the best of author's knowledge, this study is the first attempt to give comparative performance on the basis of class of institutions. The present study focuses on comparing performance of the institution with respect to change in the methodology while the other published studies referred above presented criteria level, CGPA level performance comparison region-wise in the RAF only. This study can be seen as impact of change of methodology in the specific class of institution. According to NAAC all types of colleges whether government or private, professional or traditional, rural or urban, women or coeducation are considered same however in this study there is attempt made to classify them and analyse the performance.

The performance grade-wise distribution in earlier methodology and new methodology is studied and presented in Table 8. From the results it is evident that the performance in RAF of most of the institutions is overall less in comparison to the performance in earlier methodology. In this study focus was given to analyse the reasons and several 
factors emerged out contributing to this degradation in performance; habit and practices for data maintenance were not as expected i.e. being highly data driven framework this practice hampered performance in few cases as per the feedback received from institutions. Secondly it is observed that large inter-team variation exists in assessment made by the peers visiting the institutions in earlier process, therefore the reference used for comparison in the study itself is not very reliable measure to study the performance and impact of ICT driven methodology. Thirdly introduction of some new indicators (as per changing requirements of higher education) in the framework has resulted in degradation of the performance. The continuous feedback is used as backbone and strengthened the linkage between NAAC and HEI's. Observation regarding change management at various levels of academics and administration was accounted for by providing a good level of support through helpdesk and Issue Management System (IMS). The validation of the academic data was usually found difficult due to unavailability of third-party sources. The validation method used relied mostly on the intuitional data and occasionally sourcing data from other agency such as UGC, NIRF, AISHE, other SRA's and research databases such as SCOPUS and Web of Science.

The limitation of this present analysis is that the comparison is done with earlier framework which is considerably different than the present framework in terms of methodology, criteria and indicators. Secondly the grading pattern also not remained consistently same that forms the equal base for comparison, barring all these facts this study gives quite useful results and conclusions. A component of human tendency of classification is absent by adopting RAF based framework. The data collected in RAF itself will prove to be useful for policy makers, researchers and other Quality Assurance agencies rich verified dataset of HEI's.

Disclaimer: The views expressed in this study by the author are purely personal and in no way reflect the organizational opinion.

\section{CONFLICT OF INTEREST}

The authors declare no conflict of interest.

\section{ACKNOWLEDGMENT}

The author recognises the guidance provided by former
Chairman EC NAAC, Prof. V. S. Chauhan for writing this article, also to Mr. Ansul Yadav for contributing in dataset formulation.

\section{REFERENCES}

[1] MHRD, “All India survey on higher education," 2019-20.

[2] UGC. [Online]. Available: https://www.ugc.ac.in/

[3] National policy on education (NPE 1986 as modified in 1992). [Online]. Available: https://mhrd.gov.in/sites/upload_files/mhrd/files/upload_document/N PE86-mod92.pdf

[4] NIRF. [Online]. Available: https://www.nirfindia.org/Home

[5] NBA, "National board of accreditation," 2021.

[6] GOI, "Report of the education commission 1964-66 (Kothari Commission)," Govt of India, 1964-66.

[7] J. Hoque, "Quality concern in higher education in India," EDULIGHT Journal, vol. 7, issue 13, pp. 662-668, May 2018

[8] J. D. Singh, "Higher education in India - Issues, challenges and suggestions," Higher Education, Germany: LAMBERT Academic Publishing, , 2011.

[9] J. Ahmed, A. Aurora, A. Biru and S. Salvini, "Gender issues, population and development in Ethiopia: In-depth studies from the 1994 population and housing census in Ethiopia," Roma, Italy, 2001.

[10] A. UGC. (2018). University grants commission autonomous college regulation. [Online]. Available: https://www.ugc.ac.in/pdfnews/2838506_182734.pdf

[11] NAAC. National assessment and accreditation council. Apply Online. [Online]. Available: www.naac.gov.in/apply-now

[12] K. Ravikumar, S. Samanta, A. K. Rath and S. Srinivasarangavan, Psychology and Education, pp. 5903-5914, 2021.

[13] P. Naraynan and B. S. Madhukar, "Quantitative manifesto of institutional accreditation: The building blocks of trust," presented at INQUAHE Cnferece 2019, Shrilanka, 2019.

[14] S. Amutha and B. S. Ponmudiraj, "A Symbiotic analysis of NAAC accredited higher education institutions," Journal ofthe Gujarat Research Society, pp. 57-69, 2019.

[15] P. Mukhopadhyay, M. P. Tapaswi and P. K. Sudarshan, "Assessing the quality of higher education institutions in India: An alternative framework," 2018

Copyright (C) 2022 by the authors. This is an open access article distributed under the Creative Commons Attribution License which permits unrestricted use, distribution, and reproduction in any medium, provided the original work is properly cited (CC BY 4.0).

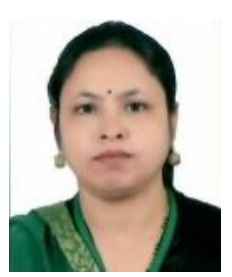

Pratibha Singh was born on 7th May 1977 in India. She is an engineer with specialization in electrical engineering. Her educational qualification is Ph.D. in electronics engineering from DAVV Indore. She has a teaching experience of 13 years in DAVV Indore. Apart from this she possesses administrative experience of $4 \mathrm{yrs}$ at NAAC as deputy adviser. Her research interest includes pattern recognition and 